\title{
ANALYSIS OF HYDROLOGICAL DROUGHT TRENDS IN THE GAP REGION (SOUTHEASTERN TURKEY) BY MANN-KENDALL TEST AND INNOVATIVE ȘEN METHOD
}

\author{
YILMAZ, B. \\ Manisa Vocational School of Technical Sciences, Manisa Celal Bayar University \\ Sehit Prof. Dr. Ilhan Varank Campus, 45140 Yunusemre, Manisa, Turkey \\ (e-mail: baris.yilmaz@cbu.edu.tr) \\ (Received $10^{\text {th }}$ Dec 2018; accepted $14^{\text {th }}$ Feb 2019)
}

\begin{abstract}
The analysis of drought trends plays a significant role in the efficient water resource management, especially in arid and semi-arid regions. Assessing the drought trends by drought indices, of which the Standardized Precipitation Index (SPI) is the most popular, is a reasonable way, because the drought indices measure the climatic anomalies through their severity, duration and frequency. In this study, the possible hydrological drought trends in the GAP region (Southeastern Turkey) were investigated by the use of 12- and 24-month SPI series. The SPI series were determined by 48 -year-long (1970-2017) monthly precipitation data monitored at nine selected stations (Mardin, Adıyaman, Batman, Diyarbakır, Siirt, Şırnak, Gaziantep, Kilis and Şanlıurfa) in the GAP region. In the analyses, a recent graphical trend detection method entitled Innovative Şen Metod (ISM) and Mann-Kendall trend test (MK) were used. The ISM has non-parametric basis without any restrictive assumption, moreover, its application is rather simple when compared with the other trend identification methods. The ability to identify the trends of low, medium and high values of a series is the innovative side of the ISM. Since the significance test is a crucial factor to identify the possible trends scientifically, the results were statistical tested at the 0.05 significance level in the methods. The ISM and MK test both revealed that, Mardin is the most vulnerable province in the region, due to the significant decreasing trend, which determined by 12-month and 24-month SPI values. Şanlıurfa, Kilis, Siirt, Diyarbakır and Batman are second order drone prone provinces. In accordance with the results of the ISM, there is an increasing trend in normal and wet conditions in Gaziantep, Şınak and Adıyaman. Specifically, the results highlight that the central of the GAP region has a tendency toward the heavier droughts in the future. It is also concluded that the ISM is a valuable tool with its simplicity as well as the inherent properties to deduce qualitative information.

Keywords: standardized precipitation index, non-parametric test, 1:1 straight line, graphical technique, sub-trends
\end{abstract}

\section{Introduction}

In recent decades, managing the water resources has become a major concern due to the impacts of climate change, which is generally characterized by increasing air temperatures and the variations in occurrence frequency and magnitude of the precipitation. Since the changing hydrological system components are not distributed uniformly, the distribution of hazardous events such as floods and droughts also varies around the world. Among these natural disasters, droughts play a more significant role due to its inherent direct effects on socio-economic development and environmental degradation. Therefore, understanding drought phenomena is paramount for the appropriate planning and management of water resources (Yevjevich et al., 1983). However, drought is a complicated phenomenon and is among the least understood natural hazards due to its multiple causing mechanisms or contributing factors operating at different temporal and spatial scales (Kiem et al., 2016).

The general approach to quantify the droughts is using indices. World Meteorological Organization (WMO) and Global Water Partnership (GWP) has given a 
wide and detailed literature and findings of drought indices for researchers in the domains of meteorology, hydrology, agricultural research and application, remote sensing, and water resources management (WMO and GWP, 2016). Using the drought indices, several researchers have analysed drought events in several parts of the world. Among the large, and still increasing number of researches, the most recent ones were Jang (2018), Buttafuoco et al. (2018), Tigkas et al. (2018), and Zhang et al. (2018).

Undoubtedly, the most well-known drought index, the Standardized Precipitation Index (SPI), suggested by McKee et al. (1993), is the most popular among the existing indices for the estimation of drought severity. One of the main advantages of SPI is that it use only precipitation data with easy calculation steps as well as flexible time scales (e.g. 1, 3, 6, 12, 24 months). Hayes et al. (2011) concluded none of the indices has the universal applicability of the SPI, and WMO has recommended the SPI as the main meteorological drought index that countries should use to monitor and follow drought conditions. It has been extensively applied in different countries (Saada and AbuRomman, 2017; Logan et al., 2010; Manatsa et al., 2010; Patel and Yadav, 2015; Raziei et al., 2009; Zhai and Feng, 2009).

On the other hand, investigations on variations of the drought characteristics are particularly important in identifying and understanding the impacts of climate change on the hydrologic cycle. To this end, the SPI trend analyses, which provide scientific information for better modeling, prediction, and control mechanism of the phenomenon concerned, are the essential efforts (Golian et al., 2015; Zhai et al., 2010; Caloiero, 2018).

There has been a wide range of researches subject to trend analyses on hydro-climate data in the literature (Fathian et al., 2014; Addisu et al., 2015; Chattopadhyay and Edwards, 2016; Bacanli, 2017; Onyutha, 2015; Zhao et al., 2015); however, they principally base on nonparametric tests, as the Mann-Kendall (MK) analysis (Mann, 1945; Kendall, 1975), the Spearman's rho (Yue et al., 2002) and the Sen trend slope calculation methodology (Sen, 1968). As Mohorji et al. (2017) concluded these objective approaches necessitate a set of assumption validity in the historical records (e.g. independent serial correlation structure, probability distribution functions, seasonality) and did not specify if low or high precipitation contributed to the detected trends (Caloiero et al., 2018). However, almost all the hydro-climate records have significant serial correlations at least on short memory basis, and efficient, effective, and optimum management of water resources requires identification of trends not only monotonically over a given time period but also whether the low, medium, and high values have separate trends (Şen, 2012, 2017). For this reason, Şen (2012) proposed the Innovative Şen Metod (ISM), which has found wide application in hydrology researches (Haktanir and Çitakoglu, 2014; Öztopal and Şen, 2017; Sonali and Kumar, 2013; Dabanli et al., 2016; Mishra and Coulibaly, 2014; Timbadiya et al., 2013). The ISM does not require any assumptions, and it base on the comparison of the two ascendingly ordered halves from the original time series.

The Southeastern Anatolia Project (in Turkish the GAP) is one of the most ambitious regional development projects in Turkey encompassing not only hydropower and irrigation infrastructure development, but also all related sectors including industry, transportation, rural and urban infrastructure, environmental protection and social sectors (Kankal et al., 2016). Therefore, an integrated approach that especially focuses on water resources is essential to achieve the planned objectives. In the GAP region, assessment of climate change impacts (e.g. floods and droughts) on water resources 
plays a crucial role, and climate change models has vital importance on achieving the project targets. To this end, trend analyses, which provide scientific information for better modeling, better prediction and better control mechanism of the phenomenon concerned, are the essential efforts.

This study aims to identify the drought-prone areas in the GAP region through the use of the SPI time series obtained for different timescales and by the Innovative Şen Metod (ISM) that allows the trend identification of the low, medium, and high values. First, the SPI values obtained at various time scales (12 and 24 months) based on 48year-long (1970-2017) precipitation data at nine selected stations (Mardin, Adiyaman, Batman, Diyarbakır, Siirt, Şırnak, Gaziantep, Kilis and Şanlıurfa) in the GAP region and then the SPI series were investigated by using the ISM and the results were compared with MK test results.

\section{Study area and data}

The Southeastern Anatolia Project region, in Turkish GAP region, spreads along 75 $10^{3} \mathrm{~km}^{2}\left(9.6 \%\right.$ of Turkey's surface area, $\left.780.610^{3} \mathrm{~km}^{2}\right)$ and includes nine provinces of Mardin, Adıyaman, Batman, Diyarbakır, Siirt, Şırnak, Gaziantep, Kilis and Şanlıurfa (Fig. 1). The Euphrates and Tigris Rivers, located in the GAP, have the largest flow volume of $16.9 \%$ and $11.4 \%$ of Turkey's average annually runoff $\left(18610^{9} \mathrm{~m}^{3}\right)$, respectively (Altinbilek and Tortajada, 2012; Kankal et al., 2016). In general, the summer season in the region is very hot and under the influence of dry and warm tropical air mass while the winter is warm and rainy. The mean annual temperature is about $18{ }^{\circ} \mathrm{C}$, due to the high summer temperatures that approach $40{ }^{\circ} \mathrm{C}$ in daytime (Yilmaz, 2018).

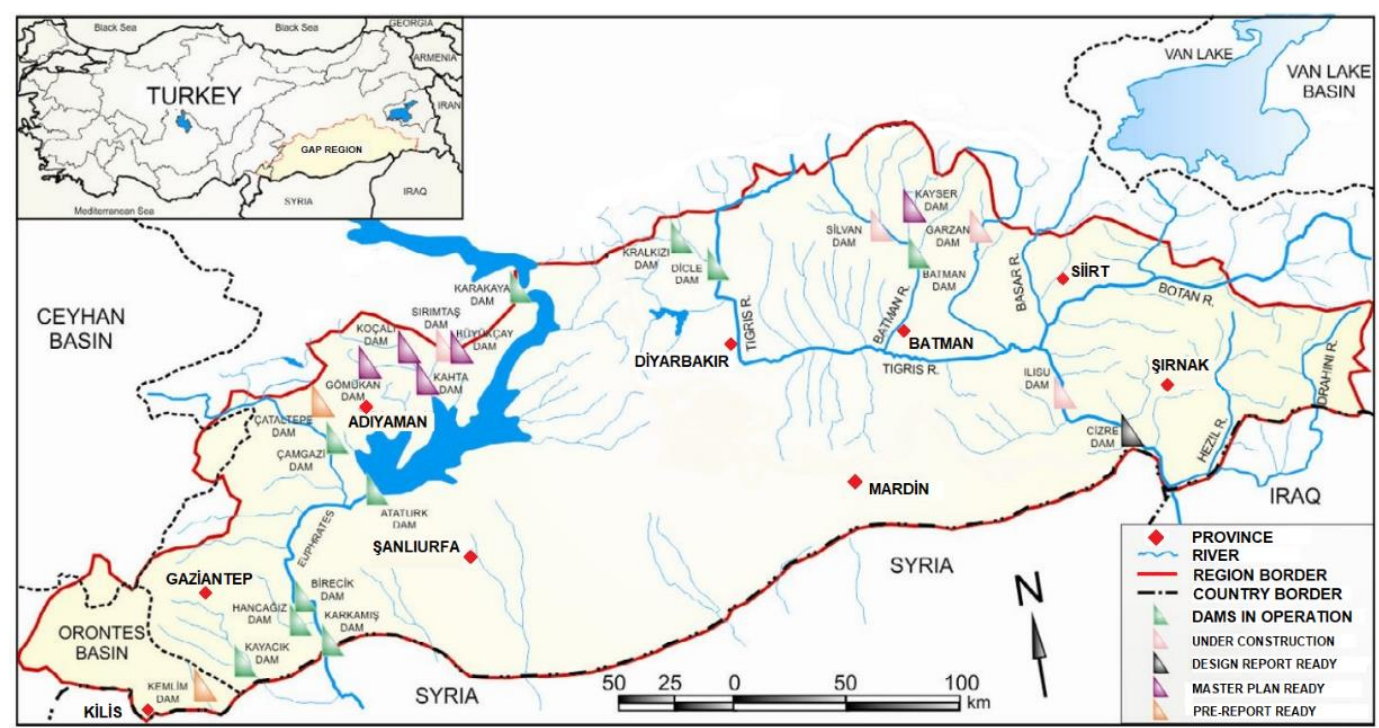

Figure 1. Water structures and provinces in the GAP region (Kankal et al., 2016)

The GAP region constitute approximately $10.7 \%$ of Turkey's total population $(80.8$ million, in 2018), and it is estimated that approximately $20 \%$ of total irrigable land and $28 \%$ of the country's energy potential are in this region (GAP, 2018). 
An irrigable area of $1810^{3} \mathrm{~km}^{2}$ is planned to be irrigated in the GAP region, and at the first stage, economically irrigable area of $10.610^{3} \mathrm{~km}^{2}$ is foreseen to be completed. The progress of the dams and hydroelectric power plants in the GAP region is presented in Figure 1 according to the project level. In the fertile lands, the agriculture is the main activity, and almost $25 \%$ of the economically active population was engaged in agriculture in 2017 (GAP, 2018). That is why the droughts have vital importance on socio-economic development in the region.

For a more detailed description of the GAP, interested readers can refer to the website published by Southeastern Anatolia Project Regional Development Administration (GAP, 2018).

In this study, the monthly precipitation data of the GAP provinces for the period 1970-2017 were obtained from the General Directorate of Meteorological Services of Ministry of Forestry and Water Affairs, Turkey. Table 1 shows the geographical coordinates, elevations and the average annual precipitation of the meteorological stations. The monthly averages of precipitation during the study period (1970-2017) and the seasonal distribution of annual precipitation are presented in Table 2. In the GAP region, the annual precipitation ranges from $431 \mathrm{~mm}$ to $697 \mathrm{~mm}$, and approximately $80 \%$ of the annual total is recorded in winter and spring seasons. Since the summer season is almost dry in the region, the irrigation is a key factor for the agriculture.

\section{Methodology}

\section{Standardized precipitation index (SPI)}

The SPI quantifies the precipitation deficit and surplus, taking into account the time series (at least 30 years long) of cumulative precipitation for various reference periods (e.g. 6, 12, and 24 months). First, an appropriate probability density distribution is fitted to the frequency distribution of cumulated precipitation and then it is subsequently converted to a standard normal distribution (Tarawneh et al., 2009). In particular, the gamma distribution (two parametric) which generally fits better to the precipitation data is used in the analyses (Ganguli and Reddy, 2014; Zhang et al., 2015). In addition, Guttman (1999) and Angelidis et al. (2012) showed that there are only minor differences between the other distributions (e.g. normal, log-normal) with respect to the results.

Table 1. The meteorological stations used in the study

\begin{tabular}{c|c|c|c|c}
\hline Stations & Station ID & Latitude $(\mathbf{N})$ & Longitude $(\mathbf{E})$ & Elevation $(\mathbf{m})$ \\
\hline Mardin & 17275 & 37.3103 & 40.7284 & 1040 \\
Adıyaman & 17265 & 37.7553 & 38.2775 & 672 \\
Batman & 17282 & 37.8636 & 41.1562 & 610 \\
Diyarbakır & 17280 & 37.8973 & 40.2027 & 674 \\
Siirt & 17210 & 37.9319 & 41.9354 & 895 \\
Şırnak & 17287 & 37.5209 & 42.4523 & 1350 \\
Gaziantep & 17261 & 37.0585 & 37.3510 & 854 \\
Kilis & 17262 & 36.7085 & 37.1123 & 640 \\
Şanlıurfa & 17270 & 37.1608 & 38.7863 & 550 \\
\hline
\end{tabular}


Table 2. The precipitation data ( $\mathrm{mm})$ and seasonal percentiles of annual precipitation (\%)

\begin{tabular}{c|c|c|c|c|c|c|c|c|c}
\hline Months & Mardin & Adıyaman & Batman & Diyarbakır & Siirt & Şırnak & Gaziantep & Kilis & Şanlıurfa \\
\hline January & 101.76 & 126.18 & 57.67 & 62.28 & 80.50 & 90.51 & 92.09 & 77.59 & 73.76 \\
February & 104.25 & 99.21 & 65.40 & 66.12 & 94.16 & 100.27 & 81.18 & 69.66 & 66.80 \\
March & 94.99 & 88.66 & 73.45 & 67.20 & 103.75 & 110.90 & 71.79 & 65.65 & 62.38 \\
April & 78.33 & 67.98 & 69.27 & 65.13 & 100.07 & 106.29 & 56.35 & 47.05 & 47.27 \\
May & 41.39 & 37.95 & 41.57 & 41.11 & 60.03 & 58.95 & 30.63 & 25.30 & 25.30 \\
June & 6.30 & 8.52 & 8.55 & 9.45 & 10.12 & 5.34 & 7.49 & 8.70 & 4.63 \\
July & 2.10 & 1.55 & 1.06 & 0.80 & 2.56 & 3.44 & 5.06 & 2.15 & 1.09 \\
August & 0.79 & 1.14 & 1.14 & 0.54 & 1.68 & 0.31 & 3.59 & 4.60 & 1.43 \\
September & 2.99 & 6.69 & 4.73 & 5.56 & 5.88 & 7.50 & 8.27 & 6.70 & 4.59 \\
October & 32.64 & 45.58 & 30.37 & 33.44 & 49.27 & 46.43 & 39.15 & 33.91 & 25.45 \\
November & 69.35 & 73.17 & 53.65 & 53.60 & 81.06 & 78.71 & 66.33 & 58.14 & 46.58 \\
December & 103.37 & 125.28 & 63.36 & 70.06 & 86.92 & 88.49 & 94.61 & 81.31 & 71.73 \\
\hline Annual & 638 & 682 & 470 & 475 & 676 & 697 & 557 & 481 & 431 \\
\hline Winter & 48.5 & 51.4 & 39.6 & 41.8 & 38.7 & 40.1 & 48.1 & 47.5 & 49.3 \\
Spring & 33.6 & 28.5 & 39.2 & 36.5 & 39.0 & 39.6 & 28.5 & 28.7 & 31.3 \\
Summer & 1.4 & 1.6 & 2.3 & 2.3 & 2.1 & 1.3 & 2.9 & 3.2 & 1.7 \\
Autumn & 16.4 & 18.4 & 18.9 & 19.5 & 20.1 & 19.0 & 20.4 & 20.5 & 17.8 \\
\hline
\end{tabular}

For a given time series of precipitation, the probability density function is defined as (Eqs. 1-2):

$$
\begin{aligned}
& g(x)=\frac{1}{\beta^{\alpha} \tau[\alpha]} x^{\alpha-1} e^{-x / \beta} \\
& \tau(\alpha)=\int_{0}^{\infty} y^{\alpha-1} e^{-y} d y
\end{aligned}
$$

where $\alpha>0$ is a shape parameter, $\beta>0$ is a scale parameter, $x>0$ is the amount of precipitation, and $\tau(\alpha)$ is the gamma function. Fitting the distribution to the data requires the estimation of shape $(\alpha)$ and scale $(\beta)$ parameters, and using the approximation of Thom (1958), these parameters are estimated as (Eq. 3):

$$
\alpha=\frac{1}{4 A}\left(1+\sqrt{1+\frac{4 A}{a}}\right) \quad \beta=\frac{g}{\alpha} \quad A=\ln (\bar{x})-\frac{\sum \ln (x)}{n}
$$

where $\mathrm{n}$ is the number of observations. Integrating the probability density function with respect to $x$ yields the following expression $\mathrm{G}(\mathrm{x})$ for the cumulative probability $(E q .4)$ :

$$
G(x)=\int_{0}^{x} g(x) d x=\frac{1}{\beta^{\alpha} \tau[\alpha]} \int_{0}^{x} x^{\alpha-1} e^{-x / \beta} d x
$$

Substituting $t=x / \beta$, Equation 4 is reduced to (Eq. 5):

$$
G(x)=\frac{1}{\pi(a)} \int_{0}^{x} t^{a-1} e^{-1} d t
$$


Since the gamma distribution is undefined for $\mathrm{x}=0$, in order to account for zero values that occur in a sample set, the cumulative probability function for gamma distribution is modified as $(E q$. O):

$$
H(x)=q+(1-q) G(x)
$$

where $q$ is the probability of zero precipitation.

Finally, the cumulative probability distribution is changed into the standard normal distribution to yield the SPI. Following the approximate conversion provided by Abramowitz and Stegun (1965), it results (Eqs. 7-8):

$$
\begin{gathered}
z=S P I=-\left(t-\frac{c_{0}+c_{1} t+c_{2} t^{2}}{1+d_{1} t+d_{2} t+d_{3} t^{3}}\right) \quad t=\sqrt{\ln \left(\frac{1}{(H(x))^{2}}\right)} \quad \text { for } 0<\mathrm{H}(\mathrm{x}) \leq 0.5 \\
z=S P I=+\left(t-\frac{\mathbb{C}_{0}+\mathbb{C}_{1} \mathrm{t} t \mathbb{C}_{2} \mathrm{t}^{2}}{1+\mathbb{d}_{1} t+\mathbb{d}_{2} t+d_{3} t^{3}}\right) \quad t=\sqrt{\ln \left(\frac{1}{[1-H(x))^{2}}\right)} \quad \text { for } 0.5<\mathrm{H}(\mathrm{x}) \leq 1.0
\end{gathered}
$$

where the mathematical constants are: $\mathrm{c}_{0}=2.515517, \mathrm{c}_{1}=0.802853, \mathrm{c}_{2}=0.010328$, $\mathrm{d}_{1}=1.432788, \mathrm{~d}_{2}=0.189269, \mathrm{~d}_{3}=0.001308$.

The average of SPI values is 0 , and the standard deviation is 1 . For the studied area and studied period, one can identify the wet and dry conditions in accordance with the classification scale of SPI (Table 3).

Table 3. Classifications scale for SPI values (Lloyd-Hughes and Saunders, 2002)

\begin{tabular}{c|c|c}
\hline SPI value & Category & Probability (\%) \\
\hline $\mathrm{SPI} \geq 2.00$ & Extremely wet & 2.3 \\
$1.50 \leq \mathrm{SPI} \leq 1.99$ & Severely wet & 4.4 \\
$1.00 \leq \mathrm{SPI} \leq 1.49$ & Moderately wet & 9.2 \\
$0.00 \leq \mathrm{SPI} \leq 0.99$ & Mildly wet & 34.1 \\
$-0.99 \leq \mathrm{SPI} \leq 0.00$ & Mild drought & 34.1 \\
$-1.49 \leq \mathrm{SPI} \leq-1.00$ & Moderately drought & 9.2 \\
$-1.99 \leq \mathrm{SPI} \leq-1.50$ & Severe drought & 4.4 \\
$\mathrm{SPI} \leq-2.00$ & Extreme drought & 2.3 \\
\hline
\end{tabular}

The SPI has the ability to reflect the impact of drought on the water resources. However, streamflow, groundwater and reservoir storage reflect the longer-term precipitation anomalies, while soil moisture conditions respond to precipitation anomalies on a relatively short scale (Tsakiris and Vangelis, 2004). In a general classification, it is possible to use the 1 to 3-month SPI for meteorological drought, 3 to 6-month SPI for agricultural drought and 12 to 24-month SPI for hydrological drought analyses and applications (Bonaccorso et al., 2003).

In this study, the SPI values at different time scales (12 and 24 months) were computed by the use of the raw precipitation data, and the software entitled SPI_SL_6.exe which could be download from the link given in the WMO (2012), is used in the calculation process. 


\section{Mann-Kendall trend test}

The non-parametric MK test (Mann, 1945; Kendall, 1975) is the most widely applied method to detect the trends in a time series. This test is based on the statistic $S(E q .9)$ :

$$
S=\sum_{k=1}^{n-1} \sum_{j=k+1}^{n} \operatorname{sgn}\left(X_{j}-X_{k}\right) \quad \operatorname{sgn}(\Phi)=\left\{\begin{array}{c}
+1 \text { if } \Phi=X_{j}-X_{k}>0 \\
0 \text { if } \Phi=X_{j}-X_{k}=0 \\
-1 \text { if } \Phi=X_{j}-X_{k}<0
\end{array}\right\}
$$

where $n$ is the number of data, $x$ is the data point at times $j$ and $k(j>k)$ and $\operatorname{sgn}(\Phi)$ is the sign function. In cases where the sample size $n \geq 10$, the mean of $S$ and variance are given by (Eq. 10-11):

$$
\begin{gathered}
E[S]=0 \\
\operatorname{var}(S)=\frac{\left[n(n-1)(2 n+5)-\sum_{i=1}^{m} t_{i}(i-1)(2 i+5)\right]}{18}
\end{gathered}
$$

where $m$ is the number of tied groups and $t_{i}$ indicates the number of data in the $i_{t h}$ tied group. The statistic $S$ is approximately normal distributed provided that the following standardized test statistics $Z$ as follows (Eq. 12):

$$
Z=\left\{\begin{array}{cl}
\frac{s-1}{\sqrt{\operatorname{var}(s)}} & s>0 \\
0 & s=0 \\
\frac{s+1}{\sqrt{\operatorname{var}(s)}} & s<0
\end{array}\right\}
$$

The positive (negative) value of $Z$ shows the upward (downward) trend. In this study, trends were tested with a significance level of $\alpha=0.05$. The null hypothesis of no trend is rejected if the absolute value of $Z$ is greater than 1.96, the critical $Z$ values at $95 \%$ two-tailed confidence intervals.

\section{Innovative Şen method (ISM)}

In the ISM, proposed by Şen (2012), the time series is divided into two equal parts, which are separately sorted in ascending order. Then, the first and the second half of the time series are located on the $x$-axis and on the $y$-axis, respectively, of a Cartesian coordinate system. If the data are collected on the $1: 1$ straight line $\left(45^{\circ}\right)$, there is no trend in the time series (Fig. 2). If data are located on the upper triangular area of the ideal line, an increasing trend in the time series exists. If data pile up in the lower (upper) triangular area of the 1:1 line, there is a decreasing (increasing) trend in the time series.

It is also possible to have time series in which there are scatter of points on both sides of 1:1 line. These cases correspond to non-monotonic trends where within the same time series there are increasing and decreasing trends at different scales even hidden ones. All possible trend types are given in (Fig. 2). Moreover, low, medium and high values of a parameter can be evaluated graphically with this method (Dabanl1 et al., 2016; Öztopal and Şen, 2017). 
The statistical significance test of the method has also proposed by Şen (2017), in which a meticulous description could be find. In short, the test is based on the construction of confidence intervals by taking into consideration the difference between two population means. Steps of this method are given by Equations 13-18.

In the equations, the notations imply as below, where, $\bar{y}_{1}$ and $\bar{y}_{2}$ : arithmetic averages of the first and the second halves of the data, $\rho$ : correlation between the first and the second halves of the data, $E(s)$ : expectation of the slope (Eq. 13), $n$ : number of data, $\sigma$ : standard deviation of all data, $\sigma_{s}$ : slope standard deviation (Eq. 14), and $s_{c r i}: \mathrm{Z}$ critical values in one-way hypothesis at $95 \%(\alpha=0.05)$ confidence level $\left(s_{c r i}= \pm 1,645\right)$.

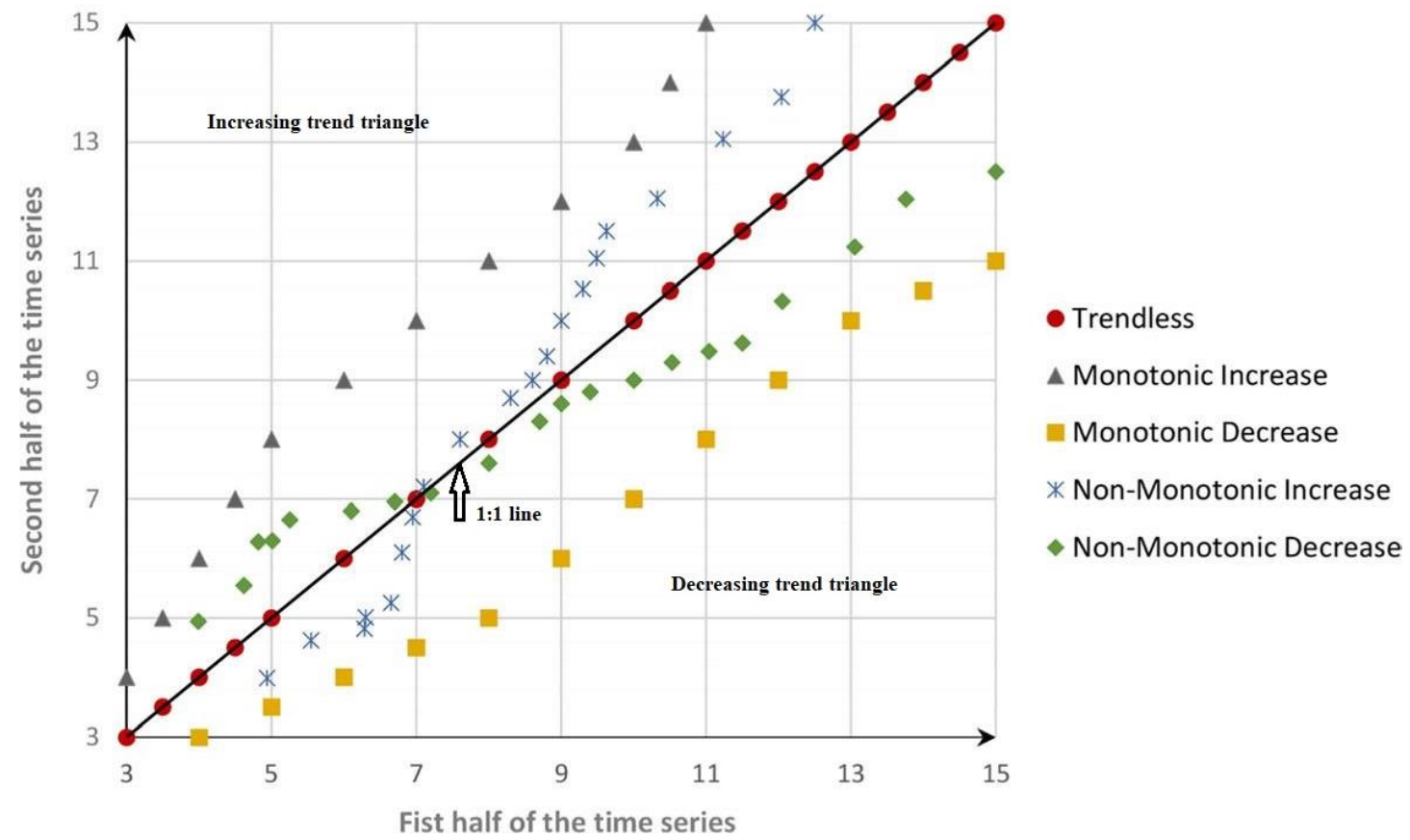

Figure 2. Illustration of trend types in the ISM (Dabanls et al., 2016)

Critical upper and lower limits calculated by Equation 18 are used to make for hypothesis test. If slope value, $s$, is outside of the lower and upper confidence limits, thus, the alternative hypothesis, $\left(H_{a}-\right.$ Yes trend $)$, is approved, otherwise the null hypothesis, $\left(H_{0}-\right.$ No trend $)$ is accepted. The type of trend depend in accordance with the slope $(s)$ sign. Slope value $(s)$ can be positive or negative. This means that there is an increasing (+) or a decreasing (-) trend in time series (Şen, 2017; Ay and Özyıldırım, 2017).

$$
\begin{gathered}
E(s)=\frac{2}{n}\left[E\left(\bar{y}_{2}\right)-E\left(\bar{y}_{1}\right)\right. \\
\sigma_{s}^{2}=\frac{4}{n^{2}}\left[E\left(\bar{y}_{2}^{2}\right)-2 E\left(\bar{y}_{2} \bar{y}_{1}\right)+E\left(\bar{y}_{1}\right)\right] \\
\rho_{\bar{y}_{2} y_{1}}=\frac{E\left(\bar{y}_{2} \bar{y}_{1}\right)-E\left(\bar{y}_{2}\right) E\left(\bar{y}_{1}\right)}{\sigma_{\left(\bar{y}_{2}\right)} \sigma_{\left(\bar{y}_{1}\right)}}
\end{gathered}
$$




$$
\begin{gathered}
\sigma_{s}^{2}=\frac{8}{n^{2}} \frac{\sigma^{2}}{n}\left(1-\rho_{\overline{y_{2} y_{1}}}\right) \\
\sigma_{s}^{2}=\frac{2 \sqrt{2}}{n \sqrt{n}} \sigma\left(1-\rho_{\overline{y_{2} y_{1}}}\right) \\
C L_{(1-\alpha)}=0 \pm s_{c r i} \sigma_{s}
\end{gathered}
$$

\section{Results and discussion}

In this study, with the aim to detect possible hydrological drought trend in the GAP region, the ISM method was applied to the 12 and 24-month SPI series. All the SPI series were divided into two 24-year sub-series: from 1970 to 1993, and from 1994 to 2017. In order to easily and better identify the possible trend of the dry, normal and wet conditions, two vertical bands have been added in Figures 3 and 4, where a red band corresponding to the drought limit (SPI $=\leq-1.0$ ) and a green band corresponding to the wet conditions limit (SPI $=\geq 1.0$ ). The area between the two bands represents the normal conditions. In the figures, 1:1 line indicates neutral (no trend) line and in the case of no trend the centroid point falls on the $1: 1$, and therefore, $E(s)=0$. Any deviation from 1:1 line indicates existence of a trend in the given variable (Şen, 2017). The arithmetic averages of the two halves appear as the centroid that falls on the trend line (red dashed line), where the vertical difference between the trend line and 1:1 line is related to the slope $(s)$ of the existing trend in the variable. The vertical distance is equal to the difference between the arithmetic means of the two halves, given as the centroid. It is obvious that in the case of increasing (decreasing) monotonic trend, the trend line falls above (below) the 1:1 line.

\section{Assessment of the 12-month drought trends}

The results of the ISM obtained by the use of 12-month SPI values was given in Figure 3, and the main findings are summarized below. In Table 4, all the necessary calculations of the ISM and the Mann-Kendall significance test results are presented.

In Mardin, there has been a decreasing trend in all SPI values, which lead to heavier droughts and weaker wet periods (Fig. 3a). It is also possible to conclude that the droughts follow a monotonic decreasing trend, and the decrement is more evident for the wet periods.

In Figure $3 b$, a slight increasing trend is significant in accordance with the ISM results. In particular, there is an increasing trend in lowest values of SPI and that demonstrates Adiyaman experienced less extreme droughts in 1994-2017 period than the 1970-1993 period. A mild increase in wet conditions is also striking.

Batman, Diyarbakır, Siirt and Şırnak have almost trendless for dry (SPI $\leq-1)$ and normal conditions; however the index values follow a decreasing trend for wet (SPI $\geq$ 1) conditions (Fig. 3c-f). Accordingly, the weaker wet periods have been evidenced.

Similar to Adiyaman, in Gaziantep, there is a general increasing trend in normal and wet conditions (Fig. 3g). However, here, both the highest and lowest SPI values increase, and that reveals Gaziantep subject to weaker extreme droughts and heavier extremely wet conditions.

In Kilis, decreasing trend in the lowest SPI values correspond heavier drought condition, and there is almost trendless series for normal and wet conditions (Fig. 3h). 
In Figure 3i, where the ISM results for Şanliurfa is illustrated, a sharp increasing trend in the lowest SPI values (weaker extreme droughts) is striking, and the normal and wet periods did not show a clear tendency.
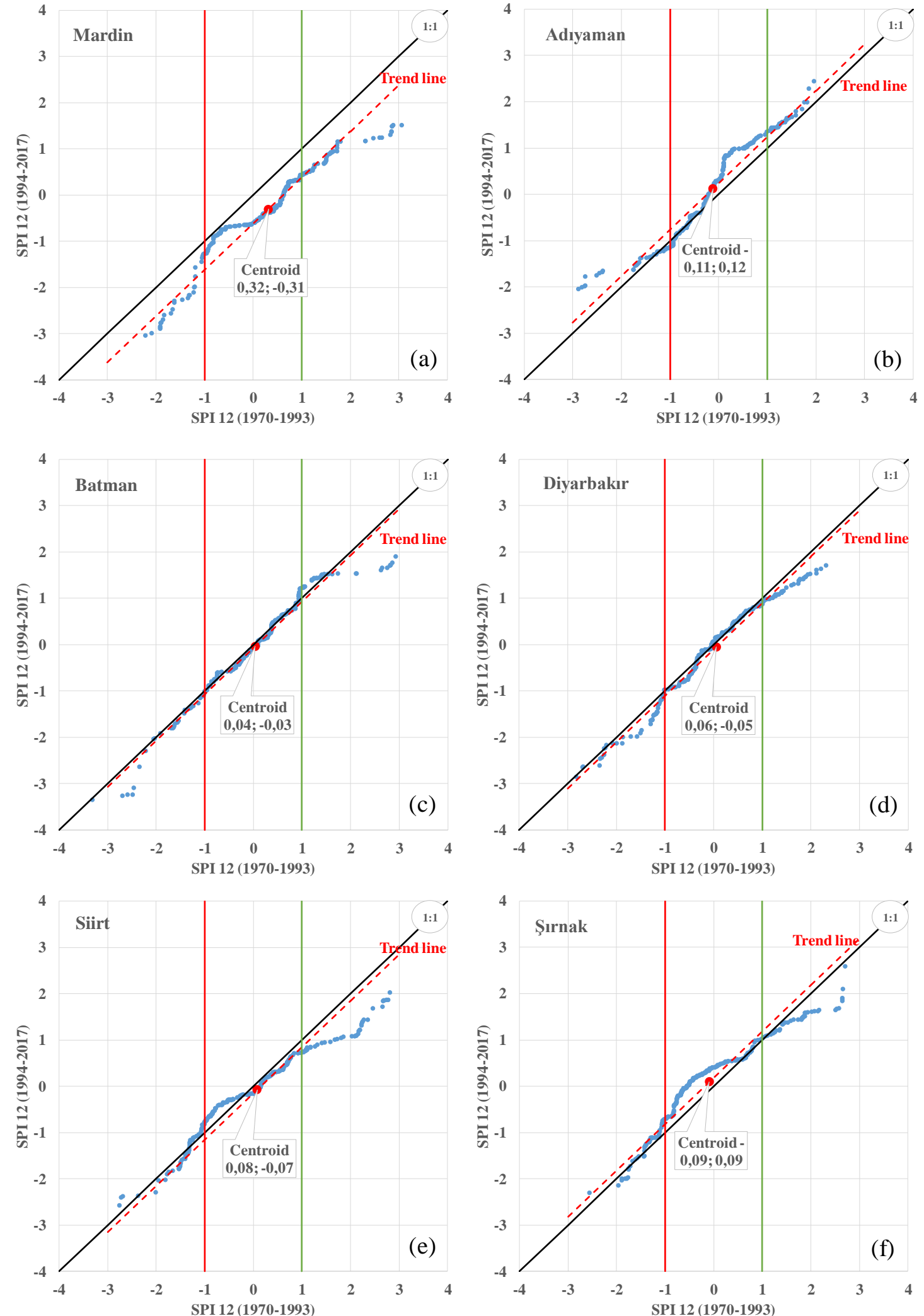

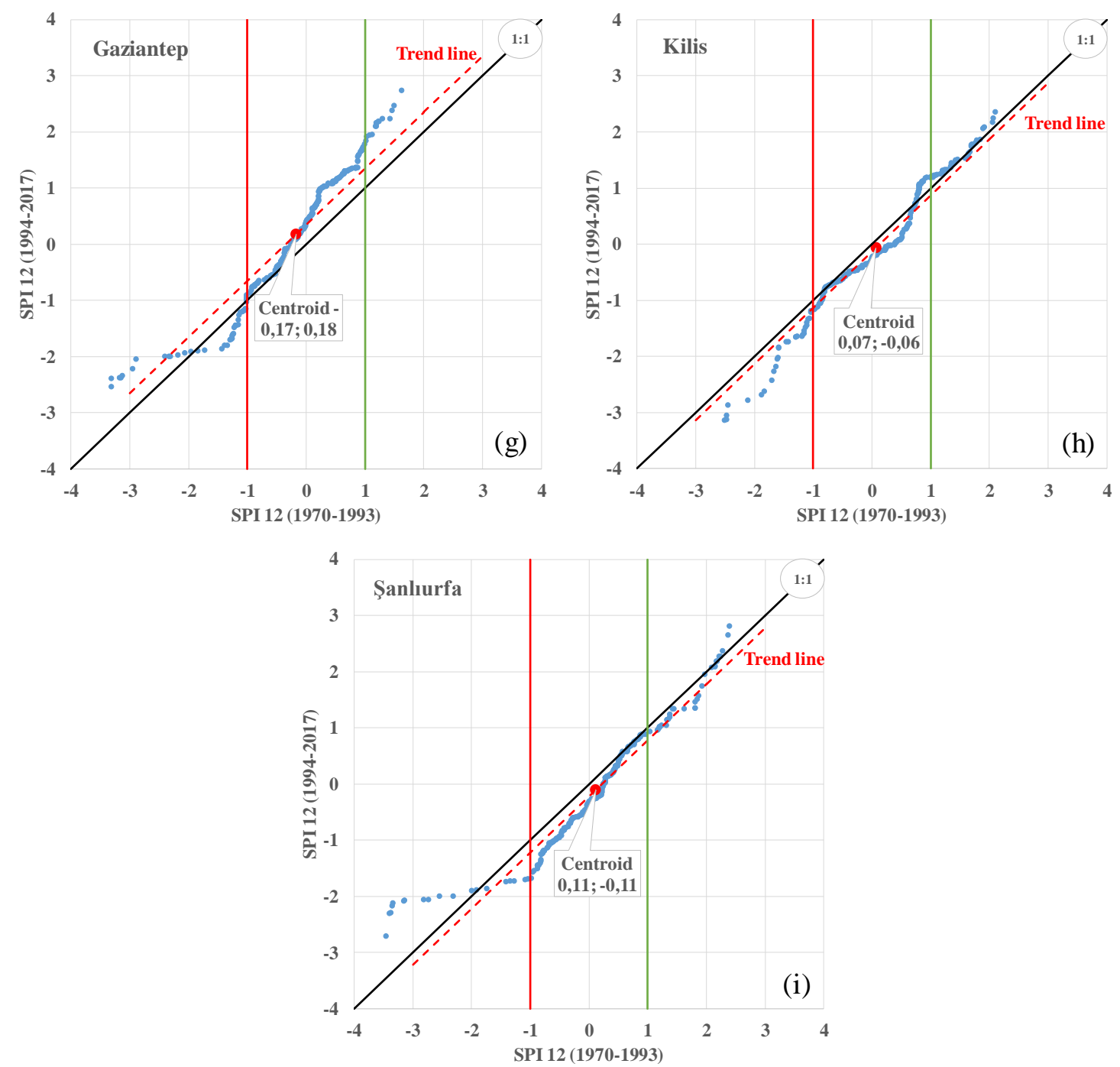

Figure 3. The scatter diagram of the ISM method for 12-month SPI in the GAP region

The ISM, a graphical trend analyses approach, allow the above qualitative analyses for dry, normal and wet conditions for the all GAP provinces. The significance analysis for both the ISM and MK test were also performed in accordance with the steps given in the previous sections. Considering the SPI-12 time series as a whole, for five provinces (Mardin, Kilis and Şanlıurfa (decreasing) and Şırnak and Gaziantep (increasing), the same results were obtained both in MK test and in the ISM (Table 4).

\section{Assessment of the 24-month drought trends}

As regards to the ISM results of 24-month SPI values, almost the same results were obtained. However, it should be noted that there is a clear increase in the trend slope for all provinces (Fig. 4). In other words, when the drought trends analyzed with a prolonged time (e.g. 24 months), the lowest SPI values follow a significant decreasing trend with respect to 12-month SPI values, excluding Şırnak and Gaziantep. Another important finding is that there is no significant increase in wet condition through the region, again excluding Gaziantep. 
Table 4. Results of ISM and MK trend tests for 12-month SPI

\begin{tabular}{|c|c|c|c|c|c|c|c|c|c|}
\hline & Mardin & Adıyaman & Batman & Diyarbakır & Siirt & Şırnak & Gaziantep & Kilis & Şanlıurfa \\
\hline Mean, $y$ & 0.002677 & 0.002855 & 0.002748 & 0.004592 & 0.002943 & 0.001312 & 0.004060 & 0.002695 & 0.003209 \\
\hline Slope, $s$ & -0.002221 & 0.000831 & -0.000247 & -0.000372 & -0.000552 & 0.000653 & 0.001239 & -0.000478 & -0.000792 \\
\hline Intercept, $a$ & 0.629025 & -0.231365 & 0.072358 & 0.109379 & 0.158688 & -0.182801 & -0.345266 & 0.137376 & 0.226649 \\
\hline Standard deviation, $\sigma$ & 1.000675 & 0.999750 & 1.000329 & 0.997984 & 0.999279 & 1.001135 & 0.998790 & 1.000167 & 0.999764 \\
\hline Correlation, $P_{y_{V_{1}}}$ & 0.96 & 0.970 & 0.973991 & 0.985 & 0.975263 & 0.957829 & 0.968268 & 0.983774 & 0.955506 \\
\hline Slope standard deviation, $\sigma_{S}$ & 0.000039 & 0.000036 & 0.000034 & 0.000026 & 0.000033 & 0.000043 & 0.000038 & 0.000027 & 0.000045 \\
\hline Lower CL (95\%) & -0.000064 & -0.000060 & -0.000056 & -0.000042 & -0.000055 & -0.000071 & -0.000062 & -0.000044 & -0.000073 \\
\hline Upper CL (95\%) & 0.000064 & 0.000060 & 0.000056 & 0.000042 & 0.000055 & 0.000071 & 0.000062 & 0.000044 & 0.000073 \\
\hline Accepted hypothesis (ISM) & $\mathrm{H}_{\mathrm{a}}$ & $\mathrm{H}_{\mathrm{a}}$ & $\mathrm{H}_{\mathrm{a}}$ & $\mathrm{H}_{\mathrm{a}}$ & $\mathrm{H}_{\mathrm{a}}$ & $\mathrm{H}_{\mathrm{a}}$ & $\mathrm{H}_{\mathrm{a}}$ & $\mathrm{H}_{\mathrm{a}}$ & $\mathrm{H}_{\mathrm{a}}$ \\
\hline Type of trend (ISM) & Decreasing & Increasing & Decreasing & Decreasing & Decreasing & Increasing & Increasing & Decreasing & Decreasing \\
\hline Sig. level, $\alpha$ (one-way) & 0.05 & 0.05 & 0.05 & 0.05 & 0.05 & 0.05 & 0.05 & 0.05 & 0.05 \\
\hline Calculated $\pm Z$ value & -8.610 & 1.222 & 0.460 & -0.687 & 0.730 & 3.131 & 1.974 & -4.881 & -4.434 \\
\hline$Z$ critical value $(\alpha=0.05)$ & \pm 1.96 & \pm 1.96 & \pm 1.96 & \pm 1.96 & \pm 1.96 & \pm 1.96 & \pm 1.96 & \pm 1.96 & \pm 1.96 \\
\hline Type of trend (MK) & Decreasing & No trend & No trend & No trend & No trend & Increasing & Increasing & Decreasing & Decreasing \\
\hline
\end{tabular}

In Mardin, an increasing trend for the extreme droughts is much more pronounced than the SPI-12 trend. It is also possible to say that a decreasing trend under normal and wet conditions (Fig. 4a).

For Adiyaman, although there is a decreasing trend in extreme droughts base on SPI12 evaluations, the ISM results of SPI-24 revealed the increasing trend in normal and wet conditions in addition to almost trendless series in extreme droughts (Fig. 4b).

Batman, Diyarbakır and Şanluurfa have an increasing trend in droughts, especially in the extreme drought cluster (Fig. $4 c-d$ and $i$ ). Moreover, a monotonic decreasing and a non-monotonic increasing trend were determined in normal conditions of Şanlurfa and Batman, respectively. The results revealed that trendless wet conditions for all provinces.

The extreme wet conditions are in a decreasing trend in Siirt (Fig. 4e), where the almost trendless series are seen in the normal and dry conditions.

In Şırnak, there is decreasing trend for the extreme droughts, and trendless series in wet conditions. An increasing trend in normal conditions also obtained by the scatter diagram (Fig. 4f).

Figure $4 g$ depicts Gaziantep with an increasing trend both in normal and wet conditions, additionally, it is very clear that there is no trend (increasing or decreasing) in droughts.

In Kilis, a slight increasing trend in wet periods is determined in addition to a mild decrease in normal conditions and trendless series in droughts (Fig. 4h).

In Table 5, the overall summary of the ISM and MK test results can be found. Similar to SPI-12 results, Mardin, Kilis and Şanliurfa follow a decreasing trend also in SPI-24 series. Here, a differentation is higher $z$ scores of MK test and higher slope values determined by ISM. Adıyaman, Şırnak and Kilis are the provinces with an increasing trend in SPI-24 values, so, they can be seen as the provinces that seem to be the most robust against drought. For Batman, Diyarbakır and Siirt, there is not a consensus between the MK and ISM, since for SPI-24 index values the MK test reveals trendless series while the ISM accept the decreasing trend.

The correlation between the trend slope values and $\mathrm{z}$ scores is explanatory for the reliability of the analyses. The correlation coefficient $(r)$ is calculated as 0.869 and 0.876 for 12 and 24 month SPI, respectively. That reveals a high correlation between MannKendall test (quantitative, non-parametric and statistical) and Innovative Şen Metod 
(qualitative and graphical). The increment in correlation is based on the number of overlapping results of the SPI-24 analysis (=6), which is more than the one in the SPI-12 analysis $(=5)$.
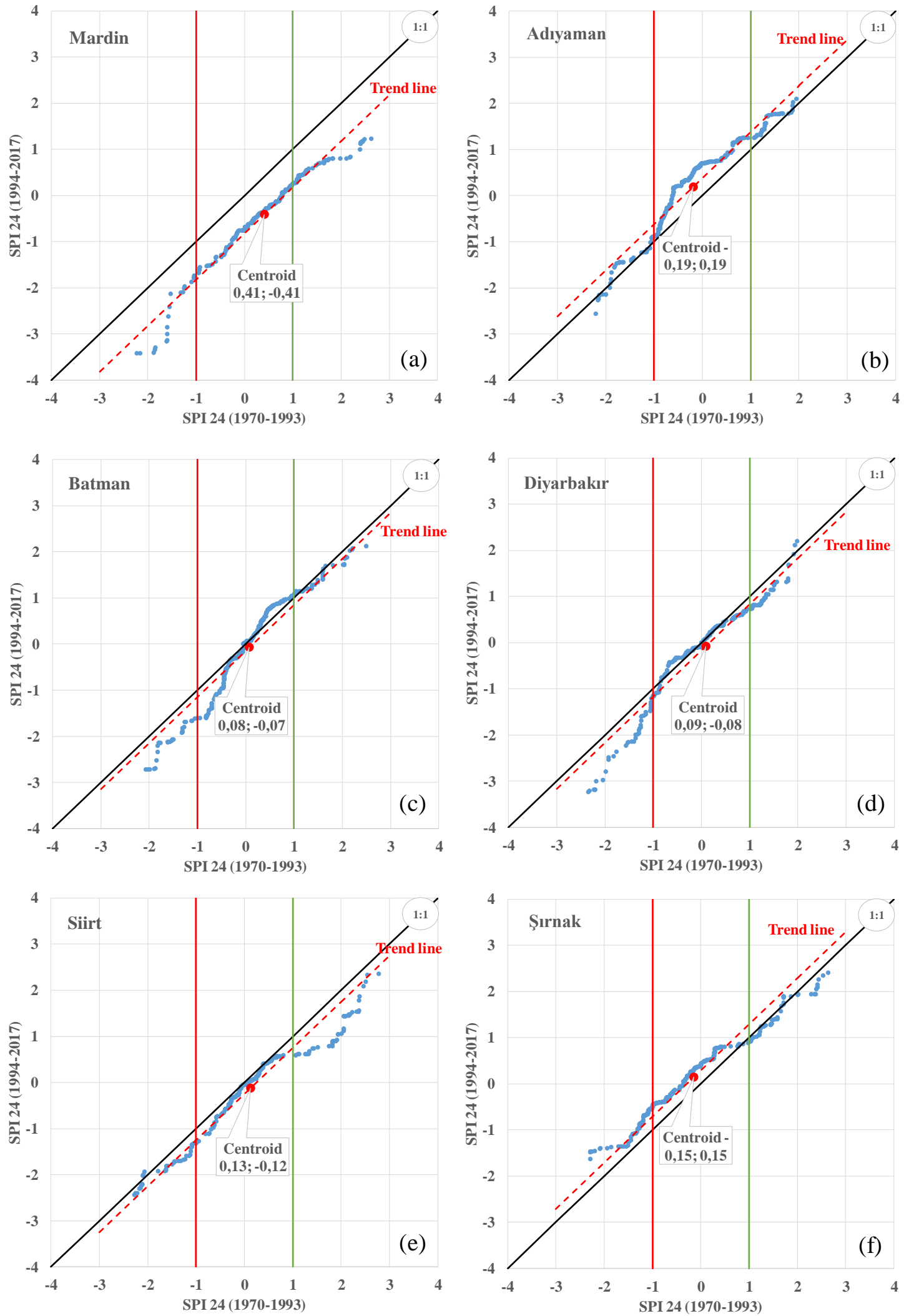

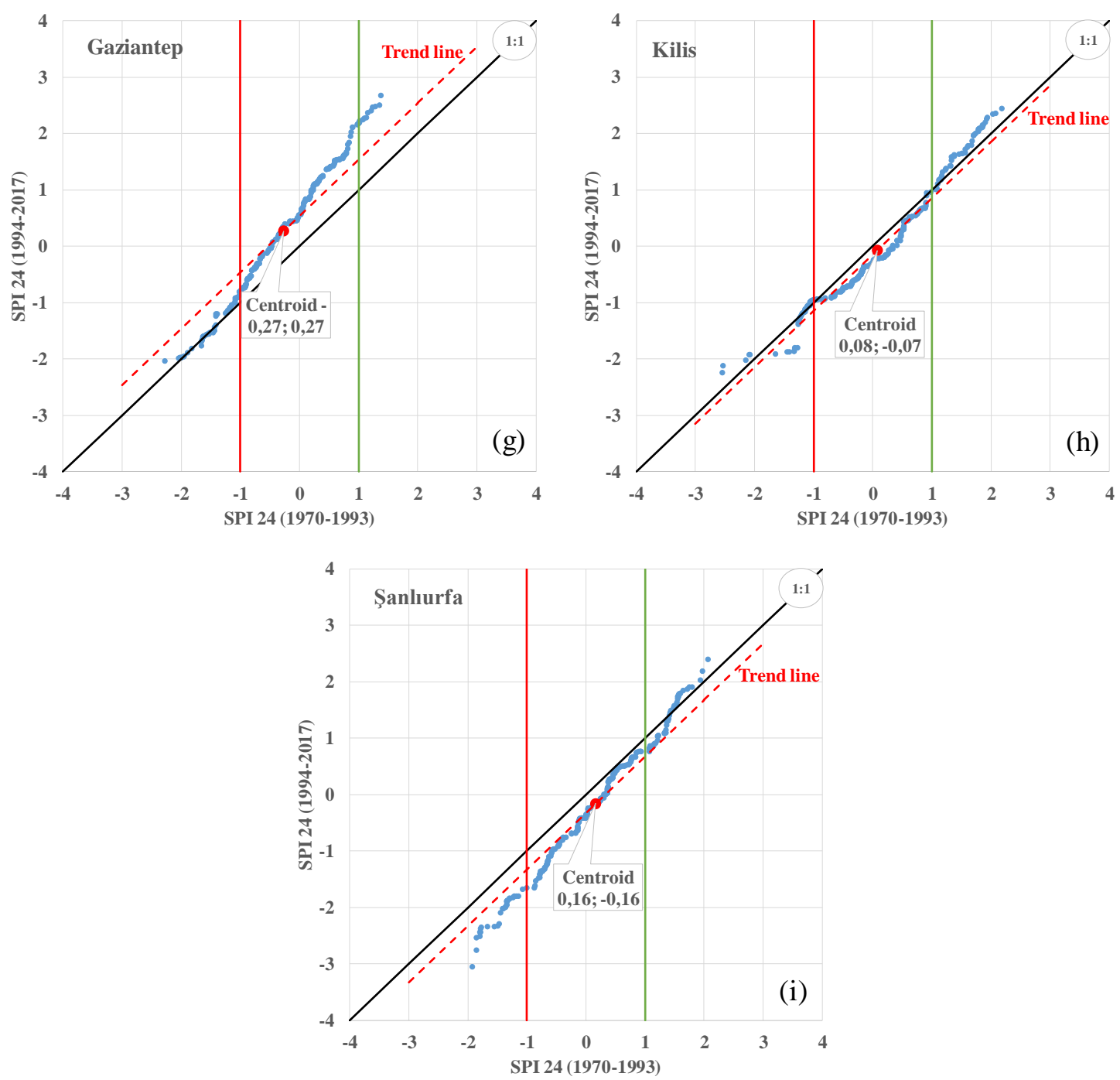

Figure 4. The scatter diagram of the ISM method for 24-month SPI in the GAP region

Table 5. Results of ISM and MK trend tests for 24-month SPI

\begin{tabular}{|c|c|c|c|c|c|c|c|c|c|}
\hline Stations & Iardin & Adıyaman & Batman & Diyarbakır & Siirt & Şırnak & Gaziantep & Kilis & Şanlıurfa \\
\hline Mean, $y$ & 0.001667 & & 0.002935 & 03243 & 0.002174 & 000000 & 02482 & .001105 & 01159 \\
\hline Slop & -0.002989 & & -0.000537 & -0.000625 & -0.000915 & 01051 & 360 & 0544 & -0.001177 \\
\hline Intercept, $a$ & 0.826594 & -0.381685 & 0.151051 & 175743 & 0.254783 & -0.290072 & -0.538424 & 0.151286 & 0.326014 \\
\hline Standard deviation, $\sigma$ & 1.001977 & 1.000445 & 0.999506 & 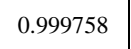 & 1.000144 & 1.001955 & .999930 & 1.001348 & 1.001712 \\
\hline Correlation, $P_{3 W_{1}}$ & 0 . & 0. & 0. & 0.969196 & 0.970922 & 0. & 0.993954 & 6 & 54 \\
\hline ope standard deviation, $\sigma_{s}$ & 0.000032 & 0.000041 & 0.000035 & 0.000038 & 0.000037 & 0.000027 & 0.000017 & 0.000030 & 0.000019 \\
\hline Lower CL & -0.000053 & -0.0 & -0.000057 & -0.000063 & -0.000 & -0.000044 & -0.000028 & 550 & 031 \\
\hline Up & 0.000053 & 0.000067 & 0.000057 & 0.000063 & 0.000061 & 0.000044 & 0.000028 & 0.000050 & 0.000031 \\
\hline Accepted hypothesis (ISM) & $\mathrm{H}_{\mathrm{a}}$ & $\mathrm{H}_{\mathrm{a}}$ & $\mathrm{H}_{\mathrm{a}}$ & $\mathrm{H}_{\mathrm{a}}$ & $\mathrm{H}_{\mathrm{a}}$ & $\mathrm{H}_{\mathrm{a}}$ & $\mathrm{H}_{\mathrm{a}}$ & $\mathrm{H}_{\mathrm{a}}$ & $\mathrm{H}_{\mathrm{a}}$ \\
\hline Type of trend (ISM) & Decreasing & Increasing & Decreasing & Decreasing & Decreasing & Increasing & Increasing & Decreasing & Decreasing \\
\hline Sig. level, $\alpha$ (one-way) & 0. & 0.05 & 0.0 & 0.0 & 0.05 & 0.0 & 0.05 & 0.05 & 0.0 \\
\hline Calculated $\pm Z$ value & -11.112 & 3.226 & 0.287 & -1.346 & 0.268 & 3.817 & 2.857 & -6.236 & -5.009 \\
\hline$Z$ critical value $(\alpha=0.05)$ & \pm 1.96 & \pm 1.96 & \pm 1.96 & \pm 1.96 & \pm 1.96 & \pm 1.96 & \pm 1.96 & \pm 1.96 & \pm 1.96 \\
\hline Type of trend (MK) & Decreasing & Increasing & No trend & No trend & No trend & Increasing & Increasing & Decreasing & Decreasing \\
\hline
\end{tabular}




\section{Conclusions}

Trend analysis is one of the most significant elements in any climate change study and provides a foresight for meteorological, hydrological, and climatological variables from past observations to future changes. The well-known trend test, Mann-Kendal (MK) trend test, which is misleading in the presence of data autocorrelation, requires few basic assumptions, which may not be valid in natural hydro-climatological time series. However, the Innovative Şen Method (ISM) does not require assumption, and it is based on the comparison of the two ascendingly ordered halves from the original time series. It also makes it possible to identify significant sub-trends of low, medium and high values. Moreover, due to its simplicity, it may be considered as a first step in the detailed climate change researches, for getting a general idea about the study area.

In this study, the ISM and the MK trend test were applied to the 12- and 24-month standardized precipitation index (SPI) time series, determined for the 1970-2017 period, in order to demonstrate the possible heydrological drought trends in the GAP region (Southeastern Turkey). Since the deficits in the precipitation reflect itself in water resources after a prolonged time, the 12- and 24-month SPI are the main index for demonstration of hydrological drought that refers to shortages of water resources in groundwater, in reservoirs or streams.

The ISM and MK test both revealed that, Mardin is the most vulnerable province in the region, due to the significant decreasing trend determined in 12-month and also in 24- month SPI values. Moreover, the increasing droughts were confirmed by the ISM for all corresponding conditions, referenced as dry, normal and wet. Şanlıurfa, Kilis, Siirt, Diyarbakır and Batman are second order drone prone provinces. In accordance with the results of the ISM, it is noted that there are an increasing trend in normal and wet conditions in Gaziantep, Şırnak and Adiyaman.

This study represent the Innovative Şen Metod with SPI values. However, future studies that focus on the similar methodologies and using the other drought indices that incorporate the evapotranspiration (e.g. Reconnaissance Drought Index) are recommended. When coupled with this study the future efforts would provide more results that are reliable for water resources managers. Moreover, since the various evapotranspiration estimation methods would differ the index values, using a wide range of estimations in the studies would provide possible trends in a more accurate and appropriate manner.

\section{REFERENCES}

[1] Abramowitz, M., Stegun, A. (eds.) (1965): Handbook of Mathematical Formulas, Graphs, and Mathematical Tables. - Dover Publications Inc, New York.

[2] Addisu, S., Selassie, Y. G., Fissha, G., Gedif, B. (2015): Time series trend analysis of temperature and rainfall in Lake Tana Sub-Basin, Ethiopia. - Environmental System Research 4(25): 01-12.

[3] Altinbilek, D., Tortajada, C. (2012): The Ataturk Dam in the Context of the Southeastern Anatolia (GAP) Project. - In: Tortajada, C., Altinbilek, D., Biswas, A. K (eds.) Impacts of Large Dams: A Global Assessment. Springer, Berlin.

[4] Angelidis, P., Maris, F., Kotsovinos, N., Hrissanthou, V. (2012): Computation of drought index SPI with alternative distribution functions. - Water Resources Management 26(9): 2453-2473. 
[5] Ay, M., Özyıldırım, S. (2017): Trend analysis of monthly total rainfall and monthly mean air temperature variables of Yozgat in Turkey. - Çukurova University Journal of the Faculty of Engineering and Architecture 32(2): 65-75.

[6] Bacanli, Ü. G. (2017): Trend analysis of precipitation and drought in the Aegean region, Turkey. - Meteorological Applications 24: 239-249.

[7] Bonaccorso, B., Bordi, I., Cancelliere, A., Rossi, G., Sutera, A. (2003): Spatial variability of drought: An analysis of SPI in Sicily. - Water Resources Management 17(4): 273-296.

[8] Buttafuoco, G., Caloiero, T., Ricca, N., Guagliardi, I. (2018): Assessment of drought and its uncertainty in a southern Italy area (Calabria region). - Measurement 113: 205-210.

[9] Caloiero, T. (2018): SPI trend analysis of New Zealand applying the ITA technique. Geosciences 8: 101.

[10] Caloiero, T., Coscarelli, R., Ferrari, E. (2018): Analysis of monthly rainfall trend in Calabria (Southern Italy) through the application of statistical and graphical techniques. Proceedings 2: 629.

[11] Chattopadhyay, S., Edwards, D. R. (2016): Long-term trend analysis of precipitation and air temperature for Kentucky, United States. - Climate 4(1): 10.

[12] Dabanl1, İ., Şen, Z., Yeleğen, M. Ö., Şişman, E., Selek, B., Güçlü, Y. S. (2016): Trend assessment by the Innovative-Şen Method. - Water Resources Management 30(5): 5193 5203.

[13] Fathian, F., Morid, S., Kahya, E. (2014): Identification of trends in hydrological and climatic variables in Urmia Lake Basin, Iran. - Theoretical and Applied Climatology 119(3): 443-464.

[14] Ganguli, P., Reddy, M. J. (2014): Evaluation of trends and multivariate frequency analysis of droughts in three meteorological subdivisions of western India. - International Journal of Climatology 34: 911-928.

[15] GAP (Southeastern Anatolia Project Regional Development Administration) (2018): Latest stage in GAP. - http://www.gap.gov.tr/gap-ta-son-durum-sayfa-32.html\#.

[16] Golian, S., Mazdiyasni, O., AghaKouchak, A. (2015): Trends in meteorological and agricultural droughts in Iran. - Theoretical and Applied Climatology 119(3-4): 679-688.

[17] Guttman, N. B. (1999): Accepting the standardized precipitation index: A calculation algorithm. - Journal of the American Water Resources Association 35(2): 311-322.

[18] Haktanir, T., Citakoglu, H. (2014): Trend, independence, stationarity, and homogeneity tests on maximum rainfall series of standard durations recorded in Turkey. - Journal of Hydrologic Engineering 19(9): 501-509.

[19] Hayes, M. J., Svoboda, M., Wall, N., Widhalm, M. (2011): The Lincoln declaration on drought indices: Universal meteorological drought index recommended. - American Meteorological Society 92(4): 485-488.

[20] Jang, D. (2018): Assessment of meteorological drought indices in Korea using RCP 8.5 scenario. - Water 10(3): 283.

[21] Kankal, M., Nacar, S., Uzlu, E. (2016): Status of hydropower and water resources in the Southeastern Anatolia Project (GAP) of Turkey. - Energy Reports 2: 123-128.

[22] Kendall, M. G. (1975): Rank Correlation Methods. - Charles Griffin, London, UK.

[23] Kiem, A. S., Johnson, F., Westra, S., van Dijk, A., Evans, J. P., O'Donnell, Rouillard, A., Barr, C., Tyler, J., Thyer, M., Jakop, D., Woldemeskel, F., Sivakumar, B., Mehrotra, R. (2016): Natural hazards in Australia: droughts. - Climatic Change 139(1): 37-54.

[24] Lloyd-Hughes, B., Saunders, M. (2002): A drought climatology for Europe. International Journal of Climatology 22: 1571-1592.

[25] Logan, K. E., Brunsell, N. A., Jones, A. R., Feddema, J. J. (2010): Assessing spatiotemporal variability of drought in the US central plains. - Journal of Arid Environment 74(2): 247-255.

[26] Manatsa, D., Mukwada, G., Siziba, E., Chinyanganya, T. (2010): Analysis of multidimensional aspects of agricultural droughts in Zimbabwe using the Standardized Precipitation Index (SPI). - Theoretical and Applied Climatology 102(3-4): 287-305. 
[27] Mann, H. B. (1945): Nonparametric tests against trend. - Econometrica 13(3): 245-259.

[28] McKee, T. B., Doesken, N. J., Kleist, J. (1993): The relationship of drought frequency and duration to time scales. - Proceedings of the AMS 8th Conference on Applied Climatology, Anaheim, CA, USA, pp. 179-184.

[29] Mishra, A. K., Coulibaly, P. (2014): Variability in Canadian seasonal streamflow information and its implication for hydrometric network design. - Journal of Hydrologic Engineering 19(8): 05014003.

[30] Mohorji, A. M., Şen, Z., Almazroui, M. (2017): Trend analyses revision and global monthly temperature innovative multi-duration analysis. - Earth Systems and Environment 1(9).

[31] Onyutha, C. (2015): Identification of sub-trends from hydro-meteorological series. Stochastic Environmental Research and Risk Assessment 30(1): 189-205.

[32] Öztopal, A., Şen, Z. (2017): Innovative trend methodology applications to precipitation records in Turkey. - Water Resources Management 31(3): 727-737.

[33] Patel, N. R., Yadav, K. (2015): Monitoring spatio-temporal pattern of drought stress using integrated drought index over Bundelkhand region, India. - Natural Hazards 77(2): 663-677.

[34] Raziei, T., Saghafian, B., Paulo, A. A., Pereira, L. S., Bordi, I. (2009): Spatial patterns and temporal variability of drought in Western Iran. - Water Resources Management 23: 439-455.

[35] Saada, N., Abu-Romman, A. (2017): Multi-site modeling and simulation of the standardized precipitation index (SPI) in Jordan. - Journal of Hydrology: Regional Studies 14: 83-91.

[36] Sen, P. K. (1968): Estimates of the regression coefficient based on Kendall's tau. Journal of the American Statistical Association 63: 1379-1389.

[37] Şen, Z. (2012): Innovative trend analysis methodology. - Journal of Hydrologic Engineering 17(9): 1042-1046.

[38] Şen, Z. (2017): Innovative trend significance test and applications. - Theoretical and Applied Climatology 127(3-4): 939-947.

[39] Sonali, P., Nagesh Kumar, D. (2013): Review of trend detection methods and their application to detect temperature changes in India. - Journal of Hydrology 476: 212-227.

[40] Tarawneh, Z. S., Elgaali, E. A., Hamdi, M. R. (2009): Bi-site analysis of meteorological drought duration: theoretical modeling and application. - Water Resources Management 23(14): 3005-3018.

[41] Thom, H. C. S. (1958): A note on the gamma distribution. - Monthly Weather Review 86(4): 117-122.

[42] Tigkas, D., Vangelis, H., Tsakiris, G. (2018): Drought characterization based on an agriculture-oriented standardized precipitation index. - Theoretical and Applied Climatology. DOI/10.1007/s00704-018-2451-3.

[43] Timbadiya, P., Mirajkar, A., Patel, P., Porey, P. (2013): Identification of trend and probability distribution for time series of annual peak flow in Tapi Basin, India. - ISH Journal of Hydraulic Engineering 19(1): 11-20.

[44] Tsakiris, G., Vangelis, H. (2004): Towards a drought watch system based on spatial SPI. - Water Resources Management 18(1): 1-12.

[45] WMO (World Meteorological Organization) (2012): Standardized Precipitation Index User Guide. - WMO No: 1090: Geneva, Switzerland.

[46] WMO and GWP (World Meteorological Organization and Global Water Partnership) (2016): Handbook of Drought Indicators and Indices. Integrated Drought Management Programme (IDMP): Integrated Drought Management Tools and Guidelines Series 2, No. 1173. - WMO, Geneva-Switzerland.

[47] Yevjevich, V., Cunha, L. D., Vlachos, E. (1983): Coping with Droughts. - Water Resources Publications, Littleton, CO, USA. 
[48] Yilmaz, B. (2018): A novel approach for drought characterization based on performanceoriented SPI: an illustrative case of Southeastern Anatolia Region, Turkey. - Applied Ecology and Environmental Research 16(5): 7289-7303.

[49] Yue, S., Pilon, P., Cavadias, G. (2002): Power of the Mann-Kendall and Spearman's Rho tests for detecting monotonic trends in hydrological series. - Journal of Hydrology 259(14): 254-271.

[50] Zhai, J., Su, B., Krysanova, V., Vetter, T., Gao, C., Jiang, T. (2010): Spatial variation and trends in PDSI and SPI indices and their relation to streamflow in 10 large regions of China. - Journal of Climate (23(3): 649-663.

[51] Zhai, L., Feng, Q. (2009): Spatial and temporal pattern of precipitation and drought in Gansu Province Northwest China. - Natural Hazards 49: 1-24.

[52] Zhang, X., Hua, Y., Feng, J., Yan, D., Liu, J., Li, C., Cheng, Y., Ren, Q. (2018): The evolution characteristics of drought and the analysis of rainfall intensity probability during alternating dry-wet change in the Haihe River basin. - Applied Ecology and Environmental Research 16(5): 6395-6407.

[53] Zhang, Y., Cai, W., Chen, Q., Yao. Y., Liu, K. (2015): Analysis of changes in precipitation and drought in Aksu River Basin, Northwest China. - Advances in Meteorology 2015: 215840.

[54] Zhao, G., Li, E., Mu, X., Wen, Z., Rayburg, S., Tian, P. (2015): Changing trends and regime shift of streamflow in the Yellow River basin. - Stochastic Environmental Research and Risk Assessment 29(5): 1331-1343. 